\title{
Images in Rheumatology
}

\section{Black-blood Magnetic Resonance Imaging in Giant Cell Arteritis}

\begin{abstract}
Jan Vynckier@, MD, Stroke Research Physician, Department of Neurology, Inselspital, Bern, Switzerland; Jelle Demeestere ${ }^{(D)}$, MD, Consultant Neurologist; Julie Lambert ${ }^{\circledR}, \mathrm{MD}$, Consultant Neuroradiologist, Department of Neurology and Department of Radiology, University Hospitals Leuven, Leuven, Belgium. Address correspondence to Dr. J. Vynckier, Inselspital, Freiburgstr. 14, 3011 Bern, Switzerland. Email: janluc.vynckier@insel.ch. Written consent from the patient could not be obtained because she had died by the time of publication.
\end{abstract}

Giant cell arteritis (GCA) affects large extracranial supraaortic arteries. Ischemic stroke is a presenting feature in up to $10 \%$ and carries a mortality rate of $75 \%$.

A 72-year-old woman was admitted with acute dizziness and jaw claudication. Clinical examination showed swollen temporal arteries, dysarthria, ataxia of the lower limbs, and left hemianopia. Erythrocyte sedimentation rate was elevated $(48 \mathrm{~mm} / \mathrm{h})$. Brain magnetic resonance imaging (MRI) showed infarction of the right occipital lobe and the cerebellar hemispheres. High-resolution black-blood contrast-enhanced T1-weighted MRI showed vessel wall enhancement of the extradural vertebral and carotid arteries as well as the temporal and occipital arteries (Figure 1). A left temporal artery biopsy was performed, confirming giant cell formation and arterial wall inflammation with lymphocytic infiltrate (Figure 2). Despite maximal therapy with dual antiplatelet therapy and high-dose methylprednisolone, the patient died after having multiple strokes, 3 weeks after admission.

The diagnosis of GCA remains challenging and often requires additional tests such as 18F-fluorodeoxyglucose positron emission tomography (FDG-PET) and biopsy. Black-blood MRI uses a prepulse for suppression of intraluminal gadolinium to create a high-contrast image of the blood vessel wall. This technique has been used for detection of vessel wall abnormalities, such as cervical dissection ${ }^{2}$ or central nervous system vasculitis

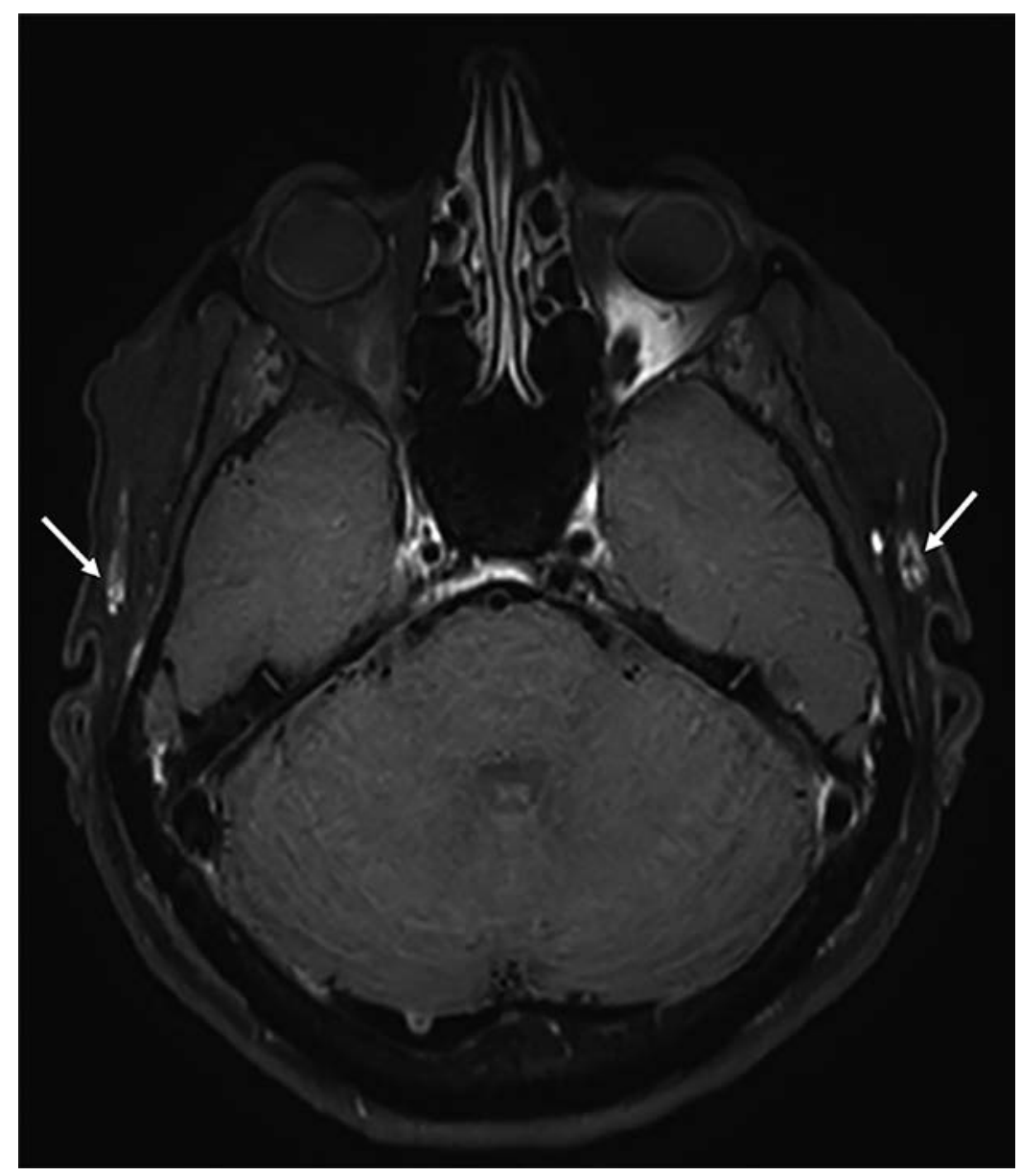

Figure 1. Axial black-blood MRI of the brain and extracranial arteries. There is contrast enhancement of the vessel wall of both temporal arteries (arrows). MRI: magnetic resonance imaging. 


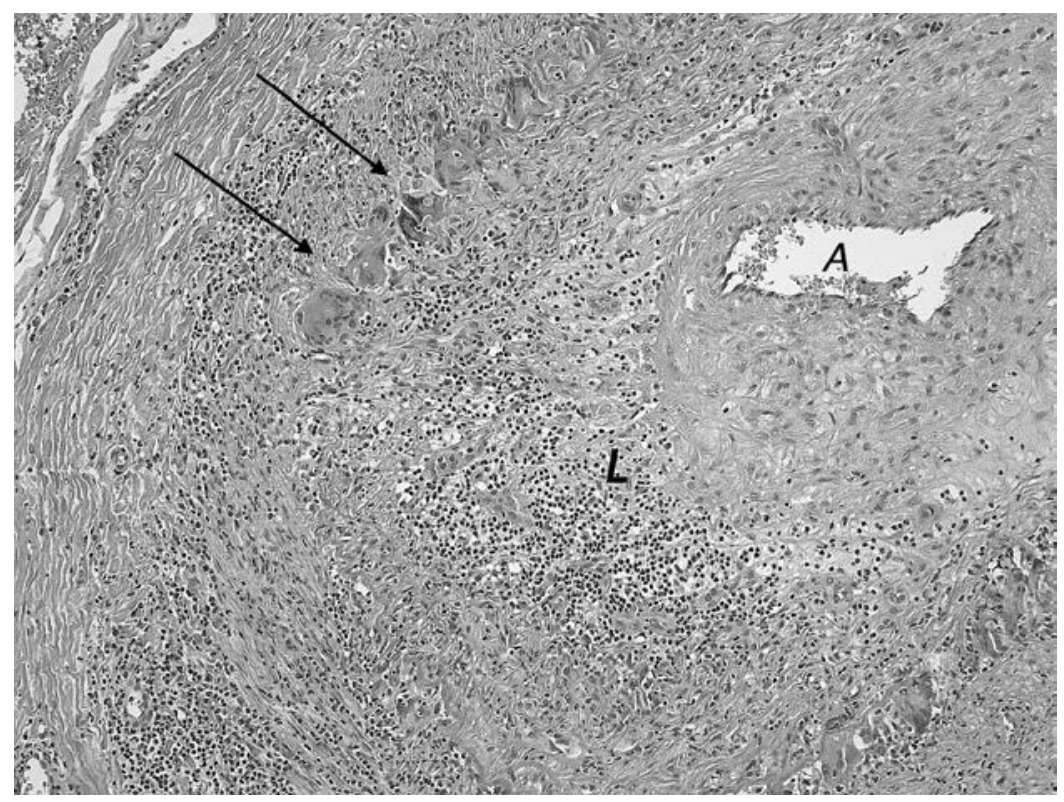

Figure 2. Histologic specimen with hematoxylin and eosin stain demonstrating a shrunken arterial lumen (A) with perivascular lymphocytic infiltrates (L) and typical giant cell formation (arrows).

and has been shown to detect arteritic anterior optic neuropathy in patients with $\mathrm{GCA}^{3}$. We report its use for diagnosis of GCA. Further studies are needed to investigate concordance between black-blood MRI and clinical symptoms, pathology, and FDG-PET.

\section{REFERENCES}

1. Samson M, Jacquin A, Audia S, Daubail B, Devilliers H, Petrella T, et al. Stroke associated with giant cell arteritis: a population-based study. J Neurol Neurosurg Psychiatry 2015;86:216-21.
2. Schwarz F, Strobl FF, Cyran CC, Helck AD, Hartmann M, Schindler A, et al. Reproducibility and differentiation of cervical arteriopathies using in vivo high-resolution black-blood MRI at $3 \mathrm{~T}$. Neuroradiology 2016;58:569-76.

3. Sommer NN, Treitl KM, Coppenrath E, Kooijman H, Dechant C, Czihal M, et al. Three-dimensional high-resolution black-blood magnetic resonance imaging for detection of arteritic anterior ischemic optic neuropathy in patients with giant cell arteritis. Invest Radiol 2018;53:698-704. 